\title{
CULTURA CONFESSIONAL E LUTA POR DIREITOS NO MUNDO DO TRABALHO: BELO HORIZONTE, 1909-1921
}

Confessional culture and struggle for rights in the world of labor: Belo Horizonte, Brazil, 1909-1921

DEIVISON AMARAL

http://dx.doi.org/10.1590/S0103-21862015000100005

Deivison Amaral é doutor em história pela Unicamp (deivisonamaral@gmail.com). A presente pesquisa recebeu auxílio da FAPESP e da CAPES.

Este artigo foi recebido em 29 de dezembro de 2014 e aprovado para publicação em 7 de abril de 2015. 


\section{RESUMO}

Este artigo analisa a luta por direitos de trabalhadores de Belo Horizonte que no início do século XX compartilharam uma cultura militante católica que influenciou sua forma de agir. A cultura confessional conformou estratégias de luta que eram favoráveis aos trabalhadores - a despeito das teses sobre cooptação -, buscavam difundir argumentos religiosos para justificar direitos e, ainda, garantir leis de proteção ao trabalhador. $\mathrm{A}$ análise da luta por direitos em Belo Horizonte mostra que os católicos inverteram a lógica de reivindicação das correntes revolucionárias - a ameaça da desordem social - e utilizaram sua representatividade e capacidade de manter a ordem social como principais instrumentos.

PalaVras-CHAVE: cultura confessional; luta por direitos; religião.

\section{AbSTRACT}

The article analyses the struggle for rights led in the early XXth century by workers of Belo Horizonte (Brazil) which shared a catholic militant culture. The confessional culture produced struggle strategies that were favourable to the workers - in spite of the theories of co-optation - and tried to spread religious arguments in order to justify rights and ensure protection laws. The analysis of the struggle led in Belo Horizonte shows that the catholics inverted the logic of revolutionary claiming - the threat of social disorder - and used their representativeness and ability to maintain social order as a main instrument.

KeYwORDs: confessional culture; struggle for rights; religion.

\section{RÉSUMÉ}

Cet article analyse la lutte pour les droits des ouvriers de Belo Horizonte (Brésil) qui au début du XXème siècle ont partagé une culture militante catholique qui a influencé leur façon d'agir. La culture confessionnelle a produit des stratégies de lutte qui étaient favorables aux ouvriers - malgré les thèses sur la cooptation - et qui cherchaient à diffuser des arguments religieux pour justifier leurs droits et assurer l'adoption de lois de protection du travail. L'analyse de la lutte pour les droits menée à Belo Horizonte montre que les catholiques ont inversé la logique d'action des révolutionnaires - c'est-à-dire la menace du désordre social - et ont utilisé leur représentatitivité et la capacité d'assurer l'ordre social comme instruments de combat.

Mots-CLÉs: culture confessionnelle; lutte pour les droits; religion. 


\section{Cultura confessional}

que significa a atribuição de uma identidade cristã em organizações de trabalhado-
res? À primeira vista, uma forma de identificar organizações cristãs no meio operário é a referência religiosa em nomes, estatutos ou programas. Embora as formas mais comuns de identificação das associações sejam a referência ao ofício e à localidade, levantamentos recentes apresentam diversas organizações de trabalhadores em que há uma referência explícita a uma identificação cristã no nome, no programa ou nos estatutos. ${ }^{1}$ No caso brasileiro, a presença de princípios cristãos em estatutos de organizações de trabalhadores não foi incomum. Esse foi o caso, por exemplo, da União Operária Beneficente de Diamantina, organização mutualista fundada em 1891 que apresentava em seus estatutos o lema "Deus, honra e trabalho", também estampado em estandartes e na própria fachada da sede social. ${ }^{2}$ Era comum, além disso, encontrar referências a São José, considerado pelos católicos o protetor dos trabalhadores. ${ }^{3}$

A frequente alusão a símbolos cristãos não garante, entretanto, que as organizações atuassem no que se pode chamar de movimento operário cristão. Nem mesmo a exclusividade de membros cristãos garantiria tal status, uma vez que é preciso considerar a forma de ação dessas organizações. 0 que definiria, então, uma associação cristã de trabalhadores? Jan de Maeyer (2005: 81-105), ao analisar a identidade cristã na organização dos trabalhadores europeus, aponta a necessidade de atentar para uma cultura confessional, expressa em práticas e valores comuns e observada na experiência. A análise das trajetórias e da experiência do trabalhador ${ }^{4}$ torna-se então mais profícua e permite perceber, dentro da cultura operária, especificidades da cultura de trabalhadores cristãos, ou de trabalhadores que compartilham a cultura militante católica. ${ }^{5}$

A cultura militante é um elemento que confere identidade ao trabalhador organizado, e no caso da cultura militante católica o que a torna específica é a centralidade do aspecto confessional na conformação de seu agir, seja nas relações cotidianas, seja na luta por direitos. Reconhecendo a complexidade das correntes ideológicas que constituíram o universo dos trabalhadores brasileiros na Primeira República, procurei entender como se conformou a cultura militante católica em Belo Horizonte, e para isso procurei observar como os elementos confessionais se relacionavam com o mundo do trabalho. 0 caso da capital mineira é exemplo 
privilegiado para a percepção desses elementos confessionais no mundo do trabalho, pois a cidade, fundada em 1897, viu florescer um movimento associativo de trabalhadores em que o catolicismo alcançou primazia em relação às outras correntes e, mais que isso, exerceu a função de organizador social, incentivando a fundação de sindicatos que na década de 1920 atuaram conjuntamente, como uma rede de organizações católicas. Embora não seja possível neste artigo dar conta da presença do catolicismo entre os trabalhadores da cidade na longa duração, é preciso destacar que a cultura militante católica alcançou a supremacia em relação às outras correntes pelo menos até a década de 1930, quando o contexto político do país e a própria orientação da Igreja mudaram a relação de forças entre os trabalhadores e suas organizações na capital mineira. ${ }^{6}$ Cabe também lembrar que esse movimento, surgido na primeira década do século XX em Belo Horizonte, foi influenciado pela doutrina social da Igreja e, no contexto específico do Brasil, pela ação restauradora do catolicismo levada a cabo pelos bispos.

A cultura confessional que conformou o tipo de associativismo experimentado em Belo Horizonte foi vista por parte da historiografia como responsável por um suposto insucesso da ação sindical na cidade. Os poucos estudos que analisaram a ação dos católicos em Belo Horizonte atribuem à Confederação Católica do Trabalho - organização congregadora de todas as outras - a culpa por um sindicalismo considerado pouco autônomo e arrefecido. Os estudos de Faria e Grossi (1982) e Dutra (1988) - destaque-se, pioneiros em analisar a questão - classificam o movimento reivindicatório dos trabalhadores em Belo Horizonte como "dócil e dentro da ordem" (1988: 172), até mesmo por sua proximidade com o poder público. ${ }^{7}$ Trata-se de uma historiografia que assumiu o discurso da produção militante e atribuiu peso excessivo ao anarquismo. Essa historiografia, ao apontar o sindicalismo revolucionário como o verdadeiro sindicalismo, acabou por ignorar o reformismo ou, quando muito, por the reservar análises pejorativas e pouco empíricas. ${ }^{8}$ Nesse tipo de produção historiográfica, o catolicismo é frequentemente associado ao conservadorismo, enquanto o anarquismo e o comunismo são identificados como modernos, sobretudo por rejeitarem os valores do capitalismo liberal e buscarem superá-lo pela revolução.

A perspectiva que adoto não se alinha a essa tipologia interpretativa e busca observar na experiência daqueles trabalhadores influenciados pela cultura confessional aspectos menos pejorativos. Trata-se, portanto, de atribuir um protagonismo ao catolicismo militante e aos trabalhadores que se filiaram a sindicatos católicos, com vista a entender sua estratégia de ação e, sobretudo, mostrar a especificidade da cultura militante católica.

A doutrina social da Igreja foi elaborada no curso do século XIX pela ação de intelectuais católicos que refletiam sobre formas de combater os males do sistema capitalista industrial 
e, ainda, por uma autocrítica da própria cúpula de Roma em relação à forma de enfrentamento do capitalismo. A pedra angular dessa doutrina foi, sem dúvida, a encíclica Rerum Novarum, de 1891, sobre a condição dos operários, quando pela primeira vez a Igreja abandonou a justificativa exclusivamente relacionada ao abandono da fé, assumiu uma questão moderna e propôs formas práticas de enfrentá-la. ${ }^{9}$

Em resumo, a encíclica reforçava o direito à propriedade privada e a necessidade de harmonia entre as classes sociais, apontando a ação católica como uma prática regeneradora dos malefícios do liberalismo moderno. Condenava as ideias socialistas e anarquistas, pois julgava serem essas ideologias desordeiras e agressoras do direito de propriedade do indivíduo. 0 documento discutia temas que, para a Igreja, eram fundamentais para a resolução da questão social, como o corporativismo, a harmonia e a cooperação entre as classes, a propriedade privada, o papel do Estado na sociedade moderna; por último, fazia a crítica do socialismo, que perpassava todos os temas anteriores. O Papa Leão XIII tentou com a Rerum Novarum lançar um projeto de transformação social que se legitimasse perante a sociedade como a verdadeira modernidade. 0 que é mais importante para a argumentação aqui desenvolvida é a defesa veemente do associativismo como forma de proteção dos trabalhadores, 0 que implicou o surgimento entre eles de um catolicismo militante, sempre em disputa com as estratégias revolucionárias.

No Brasil, o impacto da doutrina social iniciada com a Rerum Novarum não tardou a aparecer. Em contraste com o panorama europeu, onde já havia movimentos de trabalhadores cristãos organizados antes de 1891, o surgimento de movimentos sociais católicos brasileiros deu-se em decorrência da doutrina social da Igreja. ${ }^{10}$ Desde fins do século XIX, havia entre os clérigos brasileiros uma preocupação com a perda da influência política da Igreja após o advento da República e, sobretudo, com o distanciamento dos fiéis. Nesse contexto, os bispos e a militância leiga começaram um projeto político-pastoral conhecido como Restauração Católica que objetivava reconquistar o poder político da Igreja por meio da expansão territorial da sua influência (entre 1890 e 1930 foram criadas 56 novas dioceses) e da reaproximação dos fiéis. Nesse projeto, ganhou centralidade a formação de militantes que difundissem 0 catolicismo pelo país e, sobretudo, que incentivassem o associativismo baseado na doutrina social de Leão XIII. Essa militância leiga não era formada exclusivamente por trabalhadores que partilhavam uma cultura confessional, pois dela também participavam membros da elite política e patrões que podiam ter interesses próprios, muito embora a ênfase fosse dada àqueles envolvidos diretamente com a questão social. Esse contexto viu se fortalecer o catolicismo militante, formado principalmente por leigos, que impactou a organização de trabalhadores, principalmente em Belo Horizonte. 
A cultura confessional de trabalhadores, no Brasil, foi conformada nesse contexto em que a Igreja buscava expansão e investiu na formação de leigos militantes. E foi a manifestação dessa cultura confessional que marcou a especificidade dos trabalhadores adeptos da cultura militante católica. Essa especificidade era expressa principalmente pelas estratégias de ação escolhidas, que, em constante embate contra as correntes revolucionárias, ${ }^{11}$ colocavam a moral católica como elemento essencial na luta por direitos para os trabalhadores.

\section{O CATOLICISMO MILITANTE E A ORGANIZAÇÃO DOS TRABALHADORES EM BELO HORIZONTE}

$\hat{E}$ sabido que alguns estados e cidades brasileiras viram o catolicismo militante formar associações de trabalhadores ainda durante a Primeira República. São Paulo, Ceará, Pernambuco e Minas Gerais foram estados nos quais o movimento associativo católico foi mais ativo, chegando em determinados momentos a ter representação majoritária nas capitais dos dois últimos. Em São Paulo, o Centro dos Operários Católicos fundado em 1899, transformado em Centro Operário Católico Metropolitano em 1907, tinha ramificações pelos bairros da capital e em algumas cidades do interior do estado (Batalha, 2000: 28). No Ceará, o Círculo de Trabalhadores e Operários Católicos São José, fundado em Fortaleza em 1915, realizava atividades voltadas para a educação e o lazer dos trabalhadores, além de ter como finalidade expandir o circulismo no estado (Lima, 2009). Em Pernambuco, a Corporação Operária de Camaragibe e a Federação Operária Cristã foram organizações fortes, lideradas pelo industrial católico Carlos Alberto de Menezes. Em Minas Gerais, uma rede de associações católicas foi criada a partir de 1909 e atingiu o ápice com a fundação da Confederação Católica do Trabalho em Belo Horizonte em 1919. 0 catolicismo militante, contudo, não era exclusivamente voltado para os problemas dos trabalhadores. Embora o trabalhador tenha ocupado espaço de destaque nas preocupações dos militantes católicos, sobretudo pela centralidade do trabalho na questão social tal como elaborada pela Igreja, esses militantes preocupavam-se também com atividades caritativas, com o fortalecimento da religião em si e com a expansão da moral cristã na sociedade. ${ }^{12}$ Em decorrência, também havia associações pias, exclusivamente voltadas para questões religiosas ou para a formação de jovens cristãos, que se ocupavam de ações de assistência social.

Em todo o processo de gestação e implementação do projeto de restauração do catolicismo brasileiro, a consequência mais importante a se destacar dessa guinada da Igreja para Roma foi o surgimento do catolicismo militante. 0 processo de romanização criou uma nova conformação de ação eclesiástica dentro da hierarquia da Igreja, mas também fez sur- 
girem movimentos leigos guiados pelo catolicismo em várias esferas da sociedade, incluindo a organização dos trabalhadores, campo que preocupava a Igreja desde o século XIX. Nesse processo de restauração, a Igreja "elabor[ou]-se na compreensão militante de si mesma" (Silva, 2008: 541). As motivações e o percurso dessa compreensão militante no Brasil, bem como a conformação dos movimentos sociais e organizações resultantes desse catolicismo militante podem ser mais bem entendidos quando se lança o olhar sobre as manifestações do catolicismo nos primeiros anos do século XX. Nesse sentido, os congressos católicos e 0 movimento leigo organizado ao redor desses eventos fornecem elementos para compreender a conformação do catolicismo militante.

Na primeira década do século XX, em 1900 e 1908, os católicos brasileiros organizaram dois grandes congressos nacionais, respectivamente em Salvador e no Rio de Janeiro, que foram inspiradores para a ação social católica das décadas seguintes. Além desses, outros congressos regionais ou locais aconteceram em várias regiões do país, como o Congresso Católico de Pernambuco, em Recife, em 1902; o Congresso Católico de Niterói, em 1909; o Congresso Católico de Petrópolis, em 1909; o Congresso Católico Mineiro, em Juiz de Fora, em 1910, e em Belo Horizonte, em 1911, 1914 e 1918; o Congresso Católico Baiano, em Salvador, 1910. Esses eventos foram organizados por lideranças católicas leigas que, mesmo ao agir em consonância com os interesses da Igreja, não estavam subordinadas a ela. As teses finais dos dois congressos nacionais traziam vários itens relacionados à questão operária e à necessidade de incentivar o associativismo confessional entre os trabalhadores, para defender seus direitos, mas também para evitar que as culturas militantes que adotavam a ação revolucionária, como 0 anarquismo, ganhassem espaço. ${ }^{13}$

01 1 Congresso Católico Brasileiro realizou-se em 1900, em Salvador, promovido pelo Apostolado da Oração. ${ }^{14}$ É sintomático que o primeiro discurso, pronunciado por Carlos Alberto de Menezes, presidente do congresso, tratasse da questão operária e demonstrasse preocupação com a penetração de ideologias revolucionárias no meio operário.

O operário brasileiro não foi ainda trabalhado, pervertido, como o Europeu. [...] Mas se a questão não existe, existirá dentro em pouco; o terrível vírus nos é trazido por muitos veículos. 0 nosso dever é preveni-la, é aplicar ao nosso organismo social, ainda isento, a vacina que 0 torne imune. E essa vacina, nós a temos mais segura e mais eficaz que as culturas de Jenner e Pasteur. Quem nos fornece-a é a Santa Igreja [...] (Menezes, 1986: 35)

Durante o 2ํㅡㄹ Congresso Católico Brasileiro, realizado em 1908 no Rio de Janeiro, o Arcebispo Dom Joaquim Arcoverde de Albuquerque Cavalcanti anunciou que o objetivo principal dos congressistas deveria ser conceber formas de levar a doutrina católica a todas as camadas 
da sociedade. 0 programa do congresso continha temas como educação, imprensa, associações religiosas e profissionais, sindicatos, cooperativas e bancos populares, além de discussões doutrinárias. A maioria dos discursos, entretanto, apontava para a necessidade de concentrar a ação dos católicos no associativismo e na formação de militantes católicos prontos para disseminar o catolicismo social e criar as bases para a restauração da sociedade brasileira. ${ }^{15}$

Toda a mobilização em torno dos congressos católicos teve implicações diretas na formação de lideranças e no surgimento de organizações católicas. Essa agitação, que envolvia a cúpula da Igreja, mas também muito leigos, resultou no surgimento de um catolicismo militante bastante atuante. A principal decisão do 2 Congresso, contudo, foi a criação da União Popular do Brasil, que deveria ser a principal organização católica e expandir o catolicismo militante por todo o país.

A União Popular do Brasil, sediada no Rio de Janeiro e fundada oficialmente em maio de 1908, era inspirada no modelo da congênere Volksverein ${ }^{16}$ alemã. Incumbida de conduzir a militância católica em todo o país, foi apresentada como uma associação que "não era propriamente religiosa, nem uma sociedade beneficente, nem uma associação puramente econômico-social que se limita a fundar caixas de socorro, sindicatos, etc." , mas uma "instituição de caráter geral cujo fim é promover, por todos os meios legítimos, a ação social católica". ${ }^{17}$ Seus estatutos previam a criação de centros em todos os estados brasileiros e diretórios em todas as dioceses. ${ }^{18}$

Durante o 1ำ Congresso Católico Mineiro, realizado em Juiz de Fora, entre 1 e 6 de janeiro de 1910, a União Popular passou a ocupar papel central na organização da militância católica mineira. Sob a presidência de Joaquim Furtado de Menezes, ${ }^{19}$ o Congresso contou com 301 associações religiosas, representadas por 125 congressistas. Os principais temas discutidos foram propaganda e imprensa; mocidade católica; religião e os pobres; educação e instrução religiosa. Entre as conclusões do Congresso, figurou a decisão de solicitar ao episcopado mineiro o empenho na criação de diretórios da União Popular em suas dioceses. A entidade foi caracterizada como "a mais perfeita organização dos católicos" 20 pelos congressistas, que também decidiram pela transformação da União Popular de Belo Horizonte em Centro da União Popular em Minas Gerais, com a incumbência de organizar os futuros congressos católicos, incentivar a criação de associações congêneres e coordenar a ação dos diretórios regionais.

Em novembro de 1910, uma reunião do Centro da União Popular em Minas Gerais ofereceu evidências da capilaridade das organizações católicas no estado. Realizada em Belo Horizonte, a reunião listou 24 organizações católicas mineiras associadas, além de outros 23 delegados em outros municípios, incumbidos de formar diretórios locais. ${ }^{21}$ Isso dá a dimensão do acolhimento do projeto da União Popular em Minas Gerais já no primeiro ano de existência. 
Os congressos constituíram espaço seminal de debate de ideias e de formação de militantes católicos. A preocupação com a propaganda católica, a instrução religiosa, a associação da militância em organizações de ação social e, sobretudo, com a questão social e as condições de vida e trabalho direcionaram a discussão e a ação para a questão operária. As resoluções do 2ํCongresso Católico Mineiro, realizado em 1911 em Belo Horizonte, e promovido pelo Centro da União Popular em Minas Gerais, contêm um capítulo específico sobre a questão operária, que sintetiza as preocupações dos militantes católicos e traduz o próprio pensamento social católico que balizou a doutrina social da Igreja. Os congressistas definiram a ênfase na propaganda junto a operários, por meio da imprensa, panfletos e conferências, dos princípios expressos na encíclica Rerum Novarum, e destacaram vários pontos: a importância de combater as ideias socialistas; de defender, entre proprietários e industriais, o salário justo; de estimular a criação de escolas profissionais e noturnas para operários; de pressionar as autoridades para que se criassem boas condições para o consumo de gêneros pelos mais pobres, bem como mutualidades de consumo; de lutar de forma incisiva pela criação de programas que, por meio de leis ou de cooperativas de construção, facilitassem a resolução da questão da habitação operária. ${ }^{22}$

A capilaridade alcançada pelo catolicismo militante em Minas Gerais fez surgir um movimento sólido, que formou militantes leigos que não desprezavam o aspecto confessional de sua cultura associativa. Os debates realizados nos congressos católicos mostraram que a questão operária tinha centralidade e amadureceram a necessidade de incentivar o associativismo de trabalhadores nas bases da doutrina social da Igreja. A fundação da Confederação Católica do Trabalho (CCT) em Belo Horizonte em 1919 significou o ápice dessa articulação do catolicismo militante em torno da questão social.

A CCT não era um sindicato típico. Na verdade, a organização foi constituída para congregar em torno de si sindicatos e associações católicas de trabalhadores que aceitassem agir de acordo com seu programa. A CCT foi uma grande organizadora social, na medida em que direcionou as forças sindicais de Belo Horizonte para uma ação conjunta e, mais que isso, incentivou a criação de vários sindicatos na cidade durante a década de 1920. Embora classificada como confederação, a entidade era uma associação intersindical, profissionalmente indiferenciada, com atuação direta limitada ao espaço da cidade. A grande estrutura formada desde o início fez da CCT uma organização sólida, que influenciava inclusive organizações não congregadas.

Em seus estatutos, a CCT definia que "toda a ação operária deve obedecer aos princípios traçados na encíclica Rerum Novarum e em outros documentos pontifícios", 23 o que demonstra sua vinculação ideológica à doutrina social da Igreja. Essa vinculação pode ser facil- 
mente percebida pela análise das campanhas por direitos, sempre conduzidas com a premissa de manter a ordem social, e pelo recurso às elites políticas para garantir conquistas. Como já destacado, a perspectiva de análise deste trabalho não condena a priori a ação reformista e marcada pela moral cristã conduzida pelos católicos. Ao contrário, o objetivo é entender a estratégia de ação desse grupo e mostrar a especificidade da cultura militante católica. Com esse objetivo, cabe analisar como a CCT conduziu em Belo Horizonte, na década de 1920, a luta por direitos para os trabalhadores. Isso permite entender como a cultura confessional moldou 0 agir dos trabalhadores.

\section{LUTA POR DIREITOS: O DESCANSO DOMINICAL}

análise da cultura militante católica presente entre os trabalhadores de Belo Horizonte
mostra que militantes católicos esforçaram-se para capitanear os trabalhadores, atrair seus anseios e alimentar, por meio do apelo à moral cristã, uma forma de agir consoante à doutrina social da Igreja. Esse agir fortalecia o projeto da Igreja, que, sempre próxima desses trabalhadores, queria criar um exército de fiéis aptos a defender os valores cristãos na sociedade e, consequentemente, a alinhar sua ação sindical ao modus operandi defendido pelo catolicismo. A ação incisiva da militância católica leiga desde os primeiros anos de existência de Belo Horizonte criou as bases para o tipo de militância sindical que se conformaria na década de 1920. Com corações e mentes captados pelo catolicismo militante, reforçou-se um agir sindical que não abdicava do aspecto confessional. Não por acaso, as lutas por direitos empreendidas pelos trabalhadores de Belo Horizonte eram sempre permeadas por valores morais cristãos, que justificavam não só a estratégia sindical adotada, mas também o benefício almejado em si.

Sob a liderança da CCT, as organizações de trabalhadores da capital mineira promoveram diversas campanhas por direitos trabalhistas. Sempre determinadas pelas diretrizes da harmonia e da cooperação entre as classes, as campanhas visavam a conseguir acordos entre trabalhadores e patrões e, ainda, a converter tais benefícios em leis. Nesse aspecto, o recurso aos poderes públicos era recorrente. Entre as campanhas dirigidas pela CCT, podemos citar as que tiveram como temas a preocupação com acidentes de trabalho, o direito de associação, o abastecimento de água nos bairros operários, a realização de feiras livres para o abastecimento de gêneros de primeira necessidade, entre outras. No entanto, as campanhas que mais ocuparam as pautas de reivindicação da militância católica durante a década de 1920, auge da atuação dos sindicatos católicos, foram as relativas à jornada de trabalho e ao salário justo, às habitações operárias e ao descanso dominical. Esses três temas não eram problemas en- 
frentados na época exclusivamente por trabalhadores na capital mineira, mas coincidiam com as pautas de outras cidades brasileiras, como São Paulo e Rio de Janeiro (Hardman e Leonardi, 1991; Fausto, 1986). As três campanhas foram bastante documentadas para o caso de Belo Horizonte e lograram êxito ao ter as demandas convertidas em leis municipais, embora isso não tenha significado a resolução dos problemas.

Durante a década de 1920, os trabalhadores organizados em torno da militância católica em Belo Horizonte alcançaram uma supremacia sem precedentes em outras cidades brasileiras, se consideradas as disputas por espaço comumente vistas entre as diferentes culturas militantes. A preponderância da estratégia de ação sindical adotada pelo catolicismo, que fazia uso do recurso aos poderes públicos para conquistar benefícios para os trabalhadores, gerou interpretações historiográficas que basearam sua argumentação em uma pretensa ideia de cooptação ou de pouca combatividade. ${ }^{24}$ Quero aqui seguir outro caminho para compreender a estratégia de ação da cultura militante católica voltada para atender às demandas materiais dos trabalhadores. Se não é possível negar que a defesa de uma sociedade harmônica pela militância católica era profícua para os representantes da elite política, decerto não se pode transformar isso em assertiva em favor da tese de cooptação dos trabalhadores. Isso significaria retirar do trabalhador um papel ativo e atribuir-lhe uma função secundária em sua própria história, interpretação que não será aqui considerada. É nesse sentido que almejamos compreender a forma de agir da militância católica e avaliar em que medida as campanhas empreendidas eram ou não a favor das demandas dos trabalhadores belo-horizontinos.

A análise da campanha que se segue quer mostrar como as organizações católicas conquistaram esse apoio, bem como os instrumentos usados para barganhar benefícios e, sempre que possível, garanti-los em leis municipais. Isso pode ser percebido, por exemplo, ao acompanharmos os debates no Conselho Deliberativo municipal, nos quais argumentos confessionais foram utilizados para justificar a aprovação de determinadas leis. 0 exemplo mais claro desse tipo de argumentação encontra-se na campanha pelo descanso hebdomadário em Belo Horizonte, tido sempre como descanso dominical.

A luta pelo direito ao descanso semanal foi conduzida pela CCT, durante a década de 1920, de duas formas. A primeira, por meio de campanhas e denúncias publicadas em seu semanário. A segunda, por meio de ações reivindicativas diretas expressas em requerimentos e petições encaminhadas ao poder público, sobretudo ao Conselho Deliberativo, e pela negociação direta com os patrões, com a finalidade de convencê-los da necessidade do descanso dominical para os trabalhadores. As campanhas junto aos conselheiros municipais foram as mais comuns e profícuas, já que a estratégia sempre foi garantir direitos em leis municipais. A análise dos textos publicados no órgão de imprensa operário e dos anais do Legislativo 
municipal mostra como a argumentação da militância católica em relação ao descanso foi apropriada pelos conselheiros, e permite entender como se deu a conversão dessa demanda em lei. Para fiscalizar os locais de trabalho e apurar denúncias, a CCT criou a Comissão de Repouso Dominical e Dias Santos, que também fazia campanhas junto aos comerciantes para que estes não exigissem que seus empregados comparecessem ao trabalho em dias santos.

É preciso destacar que a luta por direitos da CCT era sempre perpassada por aspectos confessionais e que, consequentemente, não se lutava pelo descanso hebdomadário em seu sentido estrito. Inspirados no capítulo Gênesis da Bíblia sagrada, a exemplo do que era dito sobre a criação da Terra e dos seres vivos por Deus, o sétimo dia deveria ser reservado ao descanso santificado. A luta era pelo descanso dominical para que os trabalhadores pudessem reservar tal dia para repousar o corpo e a alma, para a oração e a liturgia religiosa e, ainda, para suas famílias. Ao justificar o descanso, as razões ligadas à fé e à religiosidade antecediam as condições de trabalho, bem-estar físico e mental dos trabalhadores.

0 descanso dominical é uma lei universal. Em todos os países respeita-se o domingo e esse respeito é tanto maior quanto mais culta é a nação. 0 domingo é o dia de Deus, pois concedeu ao homem seis dias para os seus interesses, reserva este para Si. O homem, labutando a semana inteira, deve reservar um dia para, de modo especial, honrar Aquele que o criou e the concede todas as cousas.

0 domingo é o dia da alma. Durante seis dias o homem luta para conquistar principalmente 0 bem-estar material, a manutenção do corpo. No domingo, deve cessar essa luta pelo interesse corporal, para se lembrar que tem uma alma imortal e que essa alma precisa igualmente de cuidados, mais necessários quiçá que ao próprio corpo.

0 domingo é do dia do corpo. Sim, durante a semana, o operário flagelou os seus membros na roda viva de um trabalho duro, ao sol, à chuva, no seio da terra, dentro de oficinas mal arejadas e com pouca luz, dentro de um ruído ensurdecedor! No sétimo dia, é indispensável que os membros tão maltratados durante a semana repousem para não perderem suas forças mais rapidamente do que por natureza! Mas há homens que não se incomodam com Deus, nem com a alma, nem com o próprio corpo! Querem somente dinheiro e mais dinheiro! ${ }^{25}$

A estratégia inicial da CCT foi tentar pressionar o Legislativo municipal a aprovar leis específicas para cada categoria profissional. Os padeiros, carteiros e açougueiros foram categorias que tentaram, sob a liderança da CCT, conquistar o direito ao descanso dominical entre 1919 e 1921.0 desafio de convencer os legisladores da importância do descanso dominical converteu-se na principal estratégia de luta da organização católica. Tratava-se de mostrar ao 
legislador que a força de representatividade do sindicalismo católico entre os trabalhadores de Belo Horizonte era relevante e que a demanda deveria ser vista com seriedade.

Durante as discussões sobre o descanso dos padeiros, é possível perceber a argumentação dos conselheiros municipais que, em certa medida, começava a se alinhar com aquilo que defendia a militância católica. 0 relatório da Comissão de Legislação do Conselho Deliberativo adotava tom de preocupação com a questão operária, sobretudo com a suposta ameaça das estratégias revolucionárias. Embora a proximidade entre conselheiros e sindicatos católicos não seja explícita, adotava-se o mesmo discurso de profilaxia social da militância católica ao anunciar a finalidade de evitar o "maximalismo", tal como fora repetidas vezes enunciado pela CCT.

Considerando que o trabalho deve ser um meio de ganhar a subsistência e não um destruidor do organismo, provocando a morte por inanição e fadiga;

Considerando que aos legisladores cumpre voltar suas vistas sobre a organização proletária, estudando com carinho um meio de concretizar todas as ideias aventadas, a fim de evitar os horrores do maximalismo que bate à porta, a comissão de parecer requer seja pelo Conselho Deliberativo homologado o acordo já havido entre empregados padeiros e proprietários de padarias da Capital $[\ldots] .^{26}$

0 projeto no 10, aprovado em 10 de outubro de 1919, instituía o descanso dominical para os padeiros da cidade, além de definir multa para os donos de estabelecimentos que não cumprissem a determinação. ${ }^{27}$ Durante o mês de outubro de 1919, também foi aprovado projeto semelhante que estabelecia o descanso dominical para os empregados de estabelecimentos farmacêuticos. Nos anos seguintes, vários outros projetos do mesmo tipo foram propostos pela militância católica e analisados pelos legisladores. ${ }^{28} \mathrm{O}$ prefeito Afonso Vaz de Melo, contudo, vetou todas as leis sob a justificativa de que era necessário definir quais serviços essenciais deveriam ser mantidos aos domingos.

Até então, a estratégia da CCT fora incentivar negociações entre sindicatos e patrões e tentar efetivar alguns desses acordos em leis municipais para cada ofício. Essa estratégia, contudo, esbarrava na natureza de cada categoria, como no caso dos carteiros, para os quais o descanso foi negado várias vezes em decorrência da entrega de telegramas aos domingos. ${ }^{29}$ É importante destacar que as campanhas para conquistar o descanso dominical para cada categoria de forma isolada eram sempre direcionadas para a garantia do direito em lei, e por isso a aproximação com o Conselho Deliberativo de Belo Horizonte era necessária. Os sindicatos e a própria CCT estavam constantemente em contato com conselheiros e enviavam por escrito 
seus argumentos ao órgão legislativo. Tais requerimentos seguiam a argumentação religiosa, pela qual o domingo era o dia sagrado dedicado à alma e devotado às famílias, e alegavam ainda que o tempo dedicado ao descanso do corpo e ao lazer seria útil para a o aumento da produtividade do trabalhador.

0 malogro das campanhas por categoria profissional foi ensejo para um novo direcionamento, a partir de 1921, quando a CCT se reuniu com seus sindicatos filiados e com organizações de trabalhadores não filiadas - a Associação Beneficente Tipográfica, a União dos Empregados do Comércio, a União dos Operários em Calçados, o Centro dos Chauffeurspara uma ação em conjunto com vista a resolver, de forma definitiva, o problema do descanso dominical. ${ }^{30}$ As organizações passaram a requerer junto ao Conselho Deliberativo uma lei que regulamentasse o descanso dominical para todos os trabalhadores.

Em março de 1921, a CCT endereçou aos conselheiros municipais um requerimento contendo a súmula de um projeto de lei, em que se pedia a limitação do trabalho aos domingos ao estritamente necessário. No ofício, transcrito no semanário O Operário, a CCT anunciava que representava 20 categorias profissionais já organizadas em sindicatos e todos os demais trabalhadores da cidade, ainda não organizados. 0 documento reunia toda a argumentação da militância católica em prol do descanso aos domingos e ressaltava a necessidade de uma lei geral, que regulasse o trabalho dos ofícios indispensáveis e o proibisse para os restantes. 0 descanso era defendido pelos critérios religioso, baseados no Gênesis; era higiênico, por evitar que a debilidade do corpo cansado levasse doenças aos locais do trabalho; era econômico, uma vez que o trabalhador descansado produziria mais e melhor; e era social, visto que a concessão do descanso aos trabalhadores evitaria a desordem social que poderia ser causada por aqueles que não obtivessem o benefício reivindicado. ${ }^{31}$ Ademais, a CCT também publicou um apelo aos patrões, nos mesmos termos do requerimento enviado ao Conselho Deliberativo, no qual criticava de forma incisiva a "hipocrisia vergonhosa" daqueles que forçavam seus empregados a trabalharem aos domingos e convocava os patrões católicos a "disputarem a honra de ser os primeiros a dar espontaneamente o exemplo de sinceridade e de justiça social." 32

0 ponto de destaque da argumentação dos católicos era, por certo, a apresentação da noção de que, para a manutenção da ordem social, seria indispensável o atendimento das demandas dos trabalhadores. A ascendência da CCT entre as organizações católicas na cidade e seu potencial para direcionar as ações dos trabalhadores era apresentado como fator importante de barganha para conquistar direitos. 0 sindicalismo católico invertia a lógica da ação reivindicatória das correntes revolucionárias, que tentavam impor sua força pela ameaça da desordem social ou por eventuais prejuízos causados por movimentos grevistas. Ao contrário, os sindicatos católicos ofereciam a garantia da ordem social, que seria assegurada por 
um trabalhador cristão de corpo saudável e descansado e, ainda, com a alma pacificada pelo tempo dominical dedicado à Igreja e à família. Este instrumento de pressão social foi válido nesta e em outras campanhas reivindicatórias conduzidas pelos católicos e tinha certamente apelo junto às elites dirigentes, às quais não interessavam agitações sociais. Essa estratégia ganhou centralidade na ação da militância católica e, se avaliada na perspectiva da doutrina da Igreja, podia ser facilmente associada às noções de harmonia e justiça sociais. Da perspectiva do trabalhador em luta por direitos, contudo, essa estratégia reivindicatória podia ser valiosa justamente por encontrar apoio na própria classe dirigente. A recusa da classe política em atender às demandas era o principal impedimento à conquista do direito e, portanto, seu convencimento mostrava-se como elemento de eficácia que atraía o trabalhador às fileiras do sindicalismo católico. Essa é a compreensão que quero defender para o caso dos trabalhadores belo-horizontinos que se filiaram aos sindicatos católicos.

A pressão exercida pela CCT e pelos outros sindicatos e associações da cidade junto ao Conselho Deliberativo logrou êxito na medida em que os conselheiros parecem ter se comprometido não apenas com a regulamentação do descanso dos trabalhadores, mas também com a própria argumentação que o definia aos domingos. 0 conselheiro Noraldino Lima, ao discursar a seus colegas, destacou a insistência das organizações de trabalhadores em cobrar a regulamentação do descanso:

Têm chegado a este Conselho inúmeras reclamações de todos os sindicatos, associações leigas, ligas religiosas, agremiações partidárias e outras congêneres existentes na capital, pedindo com insistência a decretação de uma lei que venha a atender a essa velha aspiração das classes proletárias em torno de um assunto que anda a pedir, realmente, a atenção dos poderes públicos.

O descanso dominical é de ordem econômica, religiosa e social: econômica, porque sabido é que todo indivíduo que descansa um dia na semana adquire novas energias, readquire outras forças para melhor empreender a jornada de seis dias úteis. [...]

Religiosa, porque desde o Gênesis encontramos esse decreto eterno de que o homem deverá descansar um dia na semana para melhor atender aos seus deveres durante os dias restantes: 0 próprio Criador descansou ao termo da obra que empreendera no "fiat-lux";

Social, finalmente, porque nada mais equitativo do que o operário que trabalha seis dias consecutivos ter também a sua clareira na vida, a sua brecha para o descanso, para a família e para o lar; ${ }^{33}$

Ao incluir a dimensão religiosa em sua defesa do descanso dominical, Noraldino Lima demonstra que as campanhas da militância católica tiveram alcance no órgão deliberativo municipal. 0 argumento apresentado é consentâneo àqueles publicados pela CCT em seu ór- 
gão de imprensa durante os anos de 1919, 1920 e 1921, o que demonstra que o discurso dos sindicatos católicos reverberou entre os legisladores municipais. A evocada dimensão social da justificativa citada pelo conselheiro para a interrupção do trabalho aos domingos, que em um argumento não confessional poderia ser motivada pela necessidade de lazer, é utilizada em defesa do cuidado com a família e o lar. Essa argumentação em defesa do descanso é, portanto, confessional em duas das três dimensões. Destaque-se que Noraldino Lima foi um conselheiro bastante próximo dos trabalhadores, com intervenções constantes em defesa de leis trabalhistas, e frequentemente era convidado a participar de assembleias do Conselho Supremo da CCT. Não por acaso, o discurso do conselheiro era tão afinado com aquele publicado pela organização católica em seu semanário operário.

É evidente que pode haver uma ambiguidade na interpretação do uso do discurso dos sindicatos católicos pelo legislador que defendia a aprovação da lei. 0 discurso do conselheiro municipal, nesse caso, situa-se na fronteira entre a apropriação da doutrina social da Igreja por um representante da elite política - que também pode ser visto como um militante leigo católico - e o reconhecimento da demanda dos trabalhadores elaborada com base em uma cultura confessional que conformou a argumentação que sustentava o benefício almejado. Quero destacar, contudo, que simplesmente assumir que a defesa do benefício pelo legislador com argumentos confessionais é uma estratégia de dominação ou de busca de controle social dos trabalhadores, sem considerar que as organizações de trabalhadores se empenharam em pressionar as elites políticas para conquistar direitos, significaria ignorar o potencial de luta e pressão social exercido pelos militantes organizados, negando-lhes o protagonismo em sua própria história. Por isso, prefiro crer na ambiguidade da relação, o que é comum quando se considera a tensão social entre trabalhadores, patrões e poder público, sem negar entretanto que a pressão exercida pelas organizações de trabalhadores teve papel preponderante na decisão do legislador de defender a aprovação da lei e conceder o benefício do descanso dominical.

0 projeto de lei ㄲo 24, de autoria de Noraldino Lima, que regulamentava o descanso dominical para os trabalhadores da capital mineira, foi apresentado ainda em 1921 sem, contudo, ser aprovado naquela reunião legislativa. Somente na segunda sessão ordinária de 1922, reapresentado na ocasião pelo conselheiro Lauro Jacques, o projeto foi aprovado e convertido na Lei no 227, de 14 de outubro daquele ano. A norma estabelecia o descanso dominical obrigatório para os trabalhadores de Belo Horizonte, com algumas exceções. Deveriam manter a atividade e dar folga ao trabalhador em outro dia: o serviço doméstico indispensável, o transporte de passageiros, as casas de diversão, a limpeza pública, o serviço farmacêutico, o serviço hospitalar e o serviço de restaurantes e lanchonetes. Já as padarias, feiras de horti- 
cultura e casas de carnes deveriam funcionar apenas até às 12 horas. A venda e a distribuição de jornais e revistas eram permitidas, embora o funcionamento de oficinas tipográficas fosse proibido aos domingos. ${ }^{34}$ Na prática, a lei só era abrangente para os trabalhadores em fábricas e oficinas e para o comércio não alimentício. No contexto da Primeira República, contudo, garantir o benefício em lei da municipalidade foi uma vitória para os trabalhadores. A lei, embora previsse multa aos empregadores que não a cumprissem, não previa a garantia de que o descanso fosse remunerado ou algum tipo de proteção a trabalhadores que exercessem funções de produção de itens por quantidade para calcular o salário. Esse fator poderia torná-la ineficaz caso não fosse combinada com o controle da jornada de trabalho, outra demanda que ocupou os sindicatos no mesmo período.

As campanhas pelo descanso aos domingos para os trabalhadores de Belo Horizonte foram conduzidas pela CCT desde sua fundação, em 1919. As primeiras tentativas, que objetivavam conquistar o descanso para cada categoria individualmente, malograram mesmo quando já havia acordo entre sindicato e trabalhadores, como no caso dos padeiros. Todas as campanhas, inclusive aquela que culminou na Lei no 227, traduzem a forma de agir da militância católica, que negociava com patrões e poder público, ao mesmo tempo em que apresentava em seus jornais a argumentação que sustentava do descanso aos domingos. Essa argumentação era principalmente confessional, pois defendia o repouso para a dedicação à alma e à fé, sem contudo deixar de defender o descanso para o corpo e o lazer do trabalhador. Destaco que esse aspecto confessional, muitas vezes mandatário na argumentação em favor do benefício que se almejava, não diminuía a efetividade da conquista de um dia de descanso para os trabalhadores de Belo Horizonte. A sustentação confessional do descanso parece ter convencido os representantes do Legislativo municipal, que justificaram a lei nos mesmos termos em que a CCT o fazia.

\section{CONSIDERAÇÕES FINAIS}

$\mathrm{O}$ agir da CCT na condução da campanha pelo descanso dominical mostra o que era, na prática, a ação sindical católica. Era uma ação reformista em todos os seus aspectos. A greve não foi um recurso utilizado e sequer cogitado mesmo em uma campanha que durou mais de três anos. Ao contrário, a militância católica oferecia abertamente sua influência sobre os trabalhadores como garantia da ordem social. A ação se dava diretamente junto a políticos, que se tornavam figuras muito próximas das organizações católicas de trabalhadores. Por fim, contudo, o que se almejava de fato era a garantia do benefício em uma lei. Embora não haja espaço aqui para dissertar sobre as outras campanhas, é possível afirmar que a condução 
foi similar em todos os casos, sobretudo no das habitações populares e da regulação de um salário justo. A primeira obteve mais êxito que a segunda no que se refere à conversão de benefícios em leis municipais, mas ambas tiveram campanhas conduzidas nos mesmo termos.

A religião foi, no caso de Belo Horizonte, fundamento para a luta dos trabalhadores. As campanhas conduzidas pela militância católica carregaram a peculiaridade de sempre serem constituídas de elementos confessionais, seja na forma de agir, ao preferir a ordem e a reivindicação direta aos poderes públicos, seja na argumentação baseada na moral cristã para justificar os direitos almejados. Essa forma de agir não preteriu a intensa luta pela organização de sindicatos sólidos para representar os trabalhadores.

A cultura confessional compartilhada por trabalhadores que se associavam nas fileiras dos sindicatos católicos converteu-se em uma estratégia reivindicatória que utilizava lógica inversa àquela das correntes revolucionárias; ou seja, além de não ser ameaçada em troca de algum benefício, a ordem era oferecida como barganha por direitos. Se essa inversão pode ser vista sob a lógica dominante que defende que poder público e Igreja cooptaram esses trabalhadores, prefiro crer - e acredito ter apresentado elementos para isso - que o catolicismo militante conseguiu construir organizações sólidas justamente por apresentar uma estratégia que conquistou os corações e mentes dos trabalhadores e, principalmente, logrou êxito em conquistar alguns direitos em um contexto em que não havia leis universalizadas de proteção ao trabalho.

\section{Notas}

1 Um exemplo de levantamento recente é o dicionário de organizações operárias e militantes da cidade do Rio de Janeiro publicado por Batalha (2009).

2 Estatuto da União Operária Beneficente de Diamantina, 1893.

3 Alguns exemplos encontrados em Minas Gerais: Associação Operária Beneficente São José, Clube Operário São José, União Operária Católica São José e União Operária São José. Todas existiam nas primeiras décadas do século XX.

4 A referência aos trabalhos de E. P. Thompson é direta.

5 A conceituação de cultura militante e de sua relação com a cultura associativa dos trabalhadores baseia-se em Batalha (2004).

6 A supremacia do catolicismo como organizador social pode ser melhor entendida a partir do estudo de Eliana Dutra (1988) e também de minha tese de doutoramento.

7 Merece menção o estudo de Michel Le Ven sobre a relação entre a classe trabalhadora e o poder público, que não faz o mesmo tipo de crítica valorativa às organizações católicas, sobretudo por esclarecer a respeito da política e da ocupação espacial da cidade, além de mostrar que os imigrantes se ocuparam principalmente com atividades rurais na zona suburbana. Cf. Le Ven (1977). 
8 Essa linha de análise historiográfica encontra crítica mais incisiva em Batalha (1990: 117-127).

90 contexto de produção da encíclica foi marcado por um embate entre pensadores católicos e contrarrevolucionários e também no interior da própria Igreja. Cf. Lex Heerma van Voss (2005), especialmente a introdução, e Furlong (1994).

10 Para o caso europeu, ver Pasture (1999).

11 A constante oposição entre católicos e revolucionários não será analisada neste artigo. Cabe contudo destacar que os católicos colocavam-se em campo diametralmente oposto àquele ocupado pelos anarquistas ou comunistas e argumentavam ser inadmissível que um trabalhador católico se filiasse a um sindicato revolucionário sem abrir mão de sua fé. Por isso, apresentavam os sindicatos católicos como os verdadeiros defensores dos trabalhadores cristãos.

12 Sobre a perspectiva caritativa que a doutrina social também incentivou, Marco Antônio de Souza (2004) faz interessante relação entre o discurso social da Igreja e a formação de uma economia da caridade em Belo Horizonte. Tal estratégia sustentou uma prática de assistência social e filantrópica que, para o autor, servia também como forma de controle social de classes pobres e garantia da ordem.

13 Em Belo Horizonte, por exemplo, destacam-se a Liga pela Moralidade, propagandista da moral católica, e a União dos Moços Católicos, fundada em 1915 e que coordenou congêneres em todo o país, chegando a ter 15 mil sócios em 1928.

14 Organização de leigos católicos surgida na França no século XIX e confiada pela Santa Sé aos jesuítas, com o objetivo de formar cristãos católicos.

15 Congresso Católico Brasileiro, 2ํ, 1908. São Sebastião do Rio de Janeiro. Atas e documentos. Rio de Janeiro: Off. d'O universo, 1910.

16 A Volksverein foi criada em 1890 por Ludwig Windthors (1812-1891) com o objetivo de enfrentar as tendências revolucionárias e defender a ordem social.

17 Discurso do Sr. Dr. José Cândido de Albuquerque Mello de Mattos sobre a "União Popular". Congresso Católico Brasileiro, 2으. op. cit.

18 A voz do povo, ano 1, № 4, Bangu, 29 out. 1911.

19 À época presidente do Conselho Vicentino de Ouro Preto, Furtado de Menezes foi militante católico e político. Foi deputado federal na década de 1930.

20 Anais do Primeiro Congresso Católico Mineiro, 1910, p. 149, apud Lima (1929: 90).

21 Municípios que já possuíam diretórios em 1910: Belo Horizonte, Alvinópolis, Vila de Nova Lima, Saúde, Ponte Nova, Rio Branco, São João Nepomuceno, São João Del Rei, Conceição, Nazareth, Santo Antônio do Rio das Mortes, Itambacuri, Mosquito (Tiradentes), Santa Rita do Rio Abaixo, São Miguel do Cajuru, Porto Real, Jequeri, Urucu (Ponte Nova), São Pedro dos Ferros, São Sebastião do Entre Rios, Santo Antônio da Grama, Barra Longa, Santa Cruz do Escalvado, Rio Doce. Ver União Popular em Minas Gerais - Nossas gerências, União Popular (órgão oficial do Centro da União Popular e comissão permanente dos congressos católicos no estado de Minas Gerais), Belo Horizonte, 1910, p. 3 (Coleção Linhares - UFMG).

22 Anais do Segundo Congresso Católico Mineiro, Belo Horizonte, 1911, p. 34.

23 Confederação Católica do Trabalho, Estatutos. 
24 Por exemplo, os já citados estudos de Eliana Dutra (1988) e Faria e Grossi (1982).

25 Trabalho aos domingos, Operário, ano 1, no 1, Belo Horizonte, 19 jun. 1920, p. 3.

26 Anais do Conselho Deliberativo de Belo Horizonte, 2a Reunião, set. 1919.

27 Idem.

28 No Conselho Deliberativo, Diário de Minas, Belo Horizonte, 28 set. 1919.

29 Descanso burlado, O Operário, ano 1, ํㅡ 3, Belo Horizonte, 31 jul. 1920, p. 1.

30 Anais do Conselho Deliberativo de Belo Horizonte, 1ㄹ- Reunião ordinária, 19 mar. 1921.

31 Descanso dominical, 0 Operário, ano 1, o 20, Belo Horizonte, 24 mar. 1921, p. 2-3.

32 Apelo aos patrões, O Operário, ano 1, № 25, Belo Horizonte, 28 abr. 1921, p. 1.

33 Anais do Conselho Deliberativo de Belo Horizonte, 2ª Reunião, set. 1921.

34 Lei Municipal no 227, de 14 de outubro de 1922.

\section{REFERÊNCIAS BIBLIOGRÁFICAS}

AMARAL, Deivison. Catolicismo e trabalho: a cultura militante dos trabalhadores de Belo Horizonte (19091941). Tese (doutorado) - Universidade Estadual de Campinas, Instituto de Filosofia e Ciências Humanas, 2015.

BATALHA, Cláudio. Cultura associativa no Rio de Janeiro da Primeira República. In: SILVA, Fernando T. e FORTES, Alexandre (orgs.). Culturas de classe: identidade e diversidade na formação do operariado. Campinas: Editora Unicamp, 2004.

Dicionário do movimento operário: Rio de Janeiro do século XIX aos anos 1920, militantes e organizações. São Paulo: Editora Fundação Perseu Abramo, 2009.

. O movimento operário na Primeira República. Rio de Janeiro: Jorge Zahar, 2000.

. Uma outra consciência de classe? 0 sindicalismo reformista na Primeira República. In: Ciências Sociais Hoje. São Paulo: Vértice, 1990, p. 117-127.

CASTEL, Robert. As metamorfoses da questão social: uma crônica do salário. 5a ed. Petrópolis: Vozes, 2005.

COLLIER, Eduardo. Carlos Alberto de Menezes: pioneirismo sindical e cristianismo. Recife: Digital Graph, 1996.

CURY, Carlos. Ideologia e educação brasileira: católicos e liberais. São Paulo: Cortez, 1978.

DUTRA, Eliana Regina de Freitas. Caminhos operários nas Minas Gerais. São Paulo: Hucitec, 1988. (org.). BH: Horizontes Históricos. Belo Horizonte: C/Arte, 1996.

FARIA, Maria Auxiliadora, GROSSI, Yonne de Souza. A classe operária em Belo Horizonte: 1897-1920. In: Seminário de Estudos Mineiros, 5, 1982, Belo Horizonte. Anais... Belo Horizonte: Faculdade de Filosofia e Ciências Humanas da UFMG, 1982, p.165-213.

FAUSTO, Boris. Trabalho urbano e conflito social (1890-1920). 4ª ed. São Paulo: Difel, 1986. 
FURLONG, Paul, CURTIS, David (coaut.). The church faces the modern world: Rerum novarum and its impact. [Winteringham, Scunthorpe, S. Humberside?]: Earlsgate, 1994.

HARDMAN, Francisco Foot, LEONARDI, Victor. História da indústria e do trabalho no Brasil: das origens aos anos 20. 2a ed. rev. São Paulo: Ática, 1991.

IGREJA CATÓLICA Papa (1878-1903: Leão XIII); LEÃO XIII. Rerum Novarum: carta encíclica de sua Santidade o Papa Leão XIII sobre a condição dos operários. Disponível em http://www.vatican.va/holy_father/leo_xiii/ encyclicals/documents/hf_I-xiii_enc_15051891_rerum-novarum_po.html. Acesso em 25/02/2014

LE VEN, Michel Marie. As classes sociais e o poder político na formação espacial de Belo Horizonte (18931914). Dissertação (mestrado em Ciências Políticas) - Universidade Federal de Minas Gerais, 1977.

LIMA, Ana Cristina P. "Obreiros Pacíficos" : o círculo de operários e trabalhadores católicos São José (Fortaleza, 1915-1930). Dissertação (mestrado). Universidade Federal do Ceará, Fortaleza, 2009.

MAEYER, Jan de. The formation of a christian worker's culture in pillarized societies: Belgium, Germany and the Netherlands, c. 185-1950. In: VAN VOSS, Lex Heerma; PASTURE, Patrick; MAEYER, Jan De (ed.). Between cross and class: comparative histories of Christian labour in Europe 1840-2000. Amsterdam: Peter Lang, 2005, p. 81-102.

MARIA, Júlio. A Igreja e a República. Brasília: Câmara dos Deputados, 1981.

MARQUES, Rita de Cássia. Da romanização à terceira via: a Igreja no Brasil de 1889 a 1945. Dissertação (Mestrado em História) - Universidade Federal de Minas Gerais, 1995.

MENEZES, Carlos Alberto de, AZEVEDO, Ferdinand. Ação Social Católica no Brasil: corporativismo e sindicalismo. São Paulo: Edições Loyola, 1986.

MICELI, Sérgio. A elite eclesiástica brasileira. Rio de Janeiro: Bertrand, 1988.

PASTURE, Patrick. Histoire du syndicalisme chrétien international: la difficile recherche d'une troisième voie. Paris: L'Harmattan, 1999.

SILVA, Wellington Teodoro da. Catolicismo militante na primeira metade do século XX brasileiro. História Revista, Goiânia, v. 13, n² 2, p. 541-563, jul./dez. 2008.

SOUZA, Jessie Jane Vieira de. Círculos Operários: a Igreja Católica e o mundo do trabalho no Brasil. Rio de Janeiro: UFRJ, 2002.

SOUZA, Marco Antônio de. A economia da caridade: estratégias assistenciais e filantropia em Belo Horizonte. Belo Horizonte: Newton Paiva, 2004.

THOMPSON, E. P. A formação da classe operária inglesa. Rio de Janeiro: Paz e Terra, 1987.

VAN VOSS, Lex Heerma; PASTURE, Patrick; MAEYER, Jan De (ed.). Between cross and class: comparative histories of Christian labour in Europe 1840-2000. Amsterdam: Peter Lang, 2005.

WIRTH, John D. O fiel da balança: Minas Gerais na Federação Brasileira, 1889-1937. Rio de Janeiro: Paz e Terra, 1982. 